\title{
Optimal Security Checking
}

\author{
Meizhi Yiyang1, a \\ ${ }^{1}$ Department of Mechanics, North China Electric Power University, Baoding 071000, China; \\ a877944881@qq.com
}

Keywords: Security checkpoint; Service Model Simulation; Analytic hierarchy process

\begin{abstract}
Overelaborate procedure in security checkpoint may cause discomfort to both travelers and airlines. Based on analytic hierarchy process, we study how the traveler style may impact the security checkpoint process. We employ the method of Dimensional Analysis to determine a certain factor's importance level compared with the others (Table 2, 3,4) and its weight in total security checkpoint (Table 6, 7, 8). In the end, we propose a globally applicable policy for the security managers, followed by a brief remark about our work.
\end{abstract}

\section{Introduction}

Every airport has security checkpoint, where passengers and their baggage are screened for explosives and other dangerous items in order to keep all passengers' safe during their travel. Airport security has needed a relatively longer time needed to finish a security examination. During 2016, the U.S. Transportation Security Agency (TSA) came under sharp criticism for extremely long lines, in particular at Chicago's O'Hare international airport. The unexplained and unpredicted long lines in checkpoint can be extremely costly to passenger as they decide between arriving unnecessarily early and potentially missing their scheduled flight.

\section{The Mathematical Model Based On Analytic Hierarchy Process}

Analytic Hierarchy Process. The hierarchical model of security checkpoint are as follow[1,2,3] 


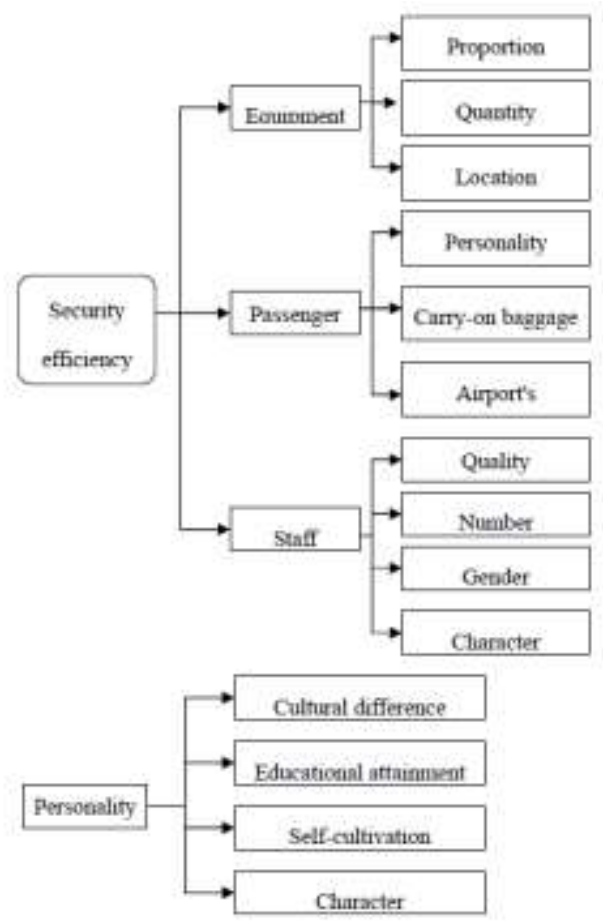

Figure 1. Hierarchy of security checkpoint

After consulting lots of literature, the variable that represent a factor's importance scale comparing with the others are listed in Table 1.

Table 1 The meaning of scale[1]

Scale
$\begin{gathered}\text { The two factors have the same importance. } \\ 3 \\ 5\end{gathered}$
The former is slightly more important than the later.
The former is obviously more important than the later.
The former is strong more important than the later.
The former is extremely more important than the later.
The intermediate values of the adjacent judgment describe above.

On the basis of data above, we obtain the judgment matrix of security efficiency, passenger, and personality. 
Table 2 Judgment matrix of security efficiency

\begin{tabular}{|c|c|c|c|}
\hline Security Efficiency & Equipment & Passenger & Staff \\
\hline Equipment & 1 & $1 / 3$ & $1 / 6$ \\
\hline Passenger & 3 & 1 & $1 / 2$ \\
\hline Staff & 6 & 2 & 1 \\
\hline \multicolumn{4}{|c|}{ Table 3 Judgment matrix of passenger } \\
\hline Passenger & Personality & $\begin{array}{c}\text { Amount of Carry-on } \\
\text { Baggage }\end{array}$ & Broadcast of airport \\
\hline Personality & 1 & $1 / 3$ & 2 \\
\hline $\begin{array}{c}\text { Amount of Carry-on } \\
\text { Baggage }\end{array}$ & 3 & 1 & 6 \\
\hline Broadcast of Airport & $1 / 2$ & $1 / 6$ & 1 \\
\hline
\end{tabular}

Table 4 Judgment matrix of security personality

\begin{tabular}{ccccc}
\hline Personality & $\begin{array}{c}\text { Cultural } \\
\text { difference }\end{array}$ & $\begin{array}{c}\text { Educational } \\
\text { attainment }\end{array}$ & Self-cultivation & Character \\
$\begin{array}{c}\text { Cultural } \\
\text { Difference }\end{array}$ & 1 & $1 / 2$ & $1 / 6$ & $1 / 6$ \\
$\begin{array}{c}\text { Educational } \\
\text { Attainment }\end{array}$ & 2 & 1 & $1 / 2$ & $1 / 3$ \\
Self-cultivation & 6 & 2 & 1 & $1 / 2$ \\
Character & 6 & 3 & 2 & 1 \\
\hline
\end{tabular}




\section{Consistency Checking}

$$
A_{1}=\left(\begin{array}{ccc}
1 & 1 / 3 & 1 / 6 \\
3 & 1 & 1 / 2 \\
6 & 2 & 1
\end{array}\right)
$$

Where:

$\mathrm{A}_{1}$ relates to Table 5;

$\gamma_{1}$ is the largest eigenvalue of security efficiency judgment matrix;

$\mathrm{n}$ is the order of matrix.

$A_{2}=\left(\begin{array}{ccc}1 & 1 / 3 & 2 \\ 3 & 1 & 6 \\ 1 / 2 & 1 / 6 & 1\end{array}\right)$

$\gamma_{2}=3 ; \mathrm{n}=3$

Where:

$\mathrm{A}_{2}$ relate to Table 6;

$\gamma_{2}$ is the largest eigenvalue of passenger judgment matrix.

$A_{3}=\left(\begin{array}{cccc}1 & 1 / 2 & 1 / 6 & 1 / 6 \\ 2 & 1 & 1 / 2 & 1 / 3 \\ 6 & 2 & 1 & 1 / 2 \\ 6 & 3 & 2 & 1\end{array}\right)$

$\gamma_{3}=4.0458 ; \mathrm{n}=4$

Where:

${ }^{A_{3}}$ relates to Table 7 ;

$\lambda_{3}$ is the largest eigenvalue of personality judgment matrix;

For $\lambda_{3}$ is not equal to 4 , we consider the consistency index CI of the personality judgment matrix:

$\mathrm{CI}=\frac{\gamma_{3}-\mathrm{n}}{\mathrm{n}-1}$

The consistency proportion $C R$ is

$\mathrm{CR}=\frac{\mathrm{CI}}{\mathrm{RI}}$

Where:

$\mathrm{RI}$ is the mean random consistency index. 
The value of RI are listed in Table 8.

Table 5 the value of $R I[4]$

\begin{tabular}{cccccccccc}
\hline$n$ & 1 & 2 & 3 & 4 & 5 & 6 & 7 & 8 & 9 \\
\hline$R I$ & 0 & 0 & 0.58 & 0.9 & 1.12 & 1.24 & 1.32 & 1.41 & 1.45 \\
\hline
\end{tabular}

Based on Eq.4, Eq.5 and Table 9, we can get the value of $C R$ personality judgment matrix:

$\mathrm{CR}=0.017<0.1$

Therefore, the consistency of personality judgment matrix is within limits of acceptability. And we further conclude that our judgment of importance between each factor is reasonable.

In addition, the effect of lower level factor to higher lever factor can be calculated as follow:

$\mathrm{W}=\frac{1}{\mathrm{n}} \sum_{\mathrm{j}=1}^{\mathrm{n}} \frac{\mathrm{a}_{\mathrm{ij}}}{\sum_{\mathrm{k}=1}^{\mathrm{n}} \mathrm{a}_{\mathrm{kj}}}$

Where:

$W_{i}$ is the weight of lower factor $i$ in higher factor.

$n$ is the order of matrix involved.

Putting the value of elements in Eq.1, Eq.2,Eq.3, we obtain:

Table 6 The influence to security checkpoint

\begin{tabular}{cccc}
\hline & Equipment & Passenger & Stuff \\
\hline Weight value & 0.0999 & 0.3000 & 0.6000 \\
\hline
\end{tabular}

Table 7 The influence to passenger factor

\begin{tabular}{ccccc}
\hline & Personality & $\begin{array}{c}\text { Amount of Carry-on } \\
\text { Romonom }\end{array}$ & Broadcast of Airport \\
\hline Weight value & \multicolumn{2}{c}{0.2222} & 0.6666 & 0.1111 \\
\hline & Table 8 & The influence to personality factor & \\
\hline & $\begin{array}{c}\text { Cultural } \\
\text { Difference }\end{array}$ & $\begin{array}{c}\text { Educational } \\
\text { Attainment }\end{array}$ & Self-cultivation & Character \\
\hline Weight value & 0.0743 & 0.1645 & 0.3389 & 0.5303 \\
\hline
\end{tabular}

Based on the data above, we figure out the weight of traveler style in the whole security checkpoint is 0.0667 . Specifically, the weight of culture difference in the whole security checkpoint is 0.0050 . 


\section{Policy and Procedural Recommendation}

- Employ staffs came from different cultural backgrounds to adapt to the cultural differences between passengers as possible.

- Adjust the number of security line and staffing in festival, holiday, or travel season.

- Open extra "fast line" for passengers who are pregnant, disabled, or in a high risk of missing his airplane.

- Set up an additional post to help passenger who are not familiar with the security checking rule, as well as to maintain order in queuing area.

- Apply face recognition system to recognize passengers with poor record for a further security checking to them.[5]

\section{Reference}

[1] Lu Xun, "Research on the Planning and Simulation of Passenger and Luggage Process at Airport Landside," Nanjing University of Aeronautics and Astronautics, 2008 .

[2] LIU Jing-li, WANG Zhi-qing, NING Xuan-xi. "Simulation Study in Passenger Process of Airport Terminal," Aeronautical Computer Technique,vol.35,No.2,pp.45-49, 2010.

[3] Arellano M, Bond S. "Some Tests of Specification for Panel Data: Monte Carlo Evidence and an Application to Employment Equations," Review of Economic studies,1991.

[4] Satty T L, "How to Make a Decision: The Analytic Hierarchy Process, "European Journal of Operational Research, 1994.

[5] Zhang Ning and Zhu Jinfu, "Design of Airport Security Checking Facial Recognition System Based on Deep Auto Encoder," Computer Measurement and Control,vol.23,No.2,pp.644-647,2015.

[6] Freud S and Chase H W, "An outline of psychoanalysis," Modern Library,1995.

[7] Robert de Lange, Ilya Samoilovich and Bo van der Rhee, "Virtual queuing at airport security lanes[J] , " European Journal of Operational Research ,2013 (1).

[8] Cope III R F, Cope R F, Davis H E, "Disney's virtual queues: Astrategic opportunity to co-brand services? " Journal of Business \& Economics Research ,2008.

[9] Narens JA, "VIRTUAL QUEUING, " Industrial Engineer: IE, 2004.

[10]S. Minkevicius, "On the Full Idle Time in Multiphase Queueing Systems[J]," Lithuanian Mathematical Journal, 2005 (3) 